\title{
Adhesion of conventional and simplified resin-based luting cements to superficial and deep dentin
}

\author{
Özcan, Mutlu ; Mese, Ayse
}

\begin{abstract}
This study evaluated the bond strengths of conventional (chemically and dual-polymerized) and simplified resin-based luting cements with their corresponding adhesives to superficial dentin (SD) and deep dentin (DD). Recently extracted third molars ( $\mathrm{N}=70, \mathrm{n}=10$ per group) were obtained and prepared for testing procedures. After using their corresponding etchants, primers, and/or adhesive systems, the conventional and simplified cements (Variolink II [group A, conventional], Bifix QM [group B, conventional], Panavia F2.0 [group C, conventional], Multilink Automix [group D, simplified], Superbond CB [group E, conventional], Clearfil Esthetic Cement [group F, simplified], Ketac-Fil [group G, conventional]) were adhered incrementally onto the dentin surfaces using polyethylene molds (inner diameter $3.5 \mathrm{~mm}$, height $5 \mathrm{~mm}$ ) and polymerized accordingly. Resinmodified glass-ionomer cement (RMGIC) acted as the control material. Shear bond strengths (1 mm/min) were determined after 500 times of thermocycling. Kruskal-Wallis and Mann-Whitney tests were used to analyze the data $(\alpha=0.05)$. Bond strength $(\mathrm{MPa})$ results were significantly affected by the cement types and their corresponding adhesive systems $(\mathrm{p} \leq 0.05)$. The shear bond strengths $(\mathrm{MPa} \pm \mathrm{SD})$ for groups A-G were $14.6 \pm 3.8,18.9 \pm 3.9$, $5.5 \pm 4.5,3.1 \pm 3.6,1.1 \pm 2.5,15.5 \pm 2.6,7 \pm 4.3$ and $7.1 \pm 5.8,15.1 \pm 7.8,8.4 \pm 7.3,7.5 \pm 7.3,4.9 \pm 5.1,12.5 \pm 2.1,6 \pm 2.6$ for SD and DD, respectively. The level of dentin depth did not decrease the bond strength significantly $(\mathrm{p}>0.05)$ for all cements, except for Variolink II $(\mathrm{p}<0.05)$. On the SD, bond strength of resin cements with "etch-and-rinse" adhesive systems (Variolink II, Bifix QM, Super-Bond CB) showed similar results being higher than those of the simplified ones. Simplified cements and RMGIC as control material showed inferior adhesion to superficial and deep dentin compared to conventional resin cements tested.
\end{abstract}

DOI: https://doi.org/10.1007/s00784-011-0594-z

Posted at the Zurich Open Repository and Archive, University of Zurich ZORA URL: https://doi.org/10.5167/uzh-62953

Journal Article

Accepted Version

Originally published at:

Özcan, Mutlu; Mese, Ayse (2012). Adhesion of conventional and simplified resin-based luting cements to superficial and deep dentin. Clinical Oral Investigations, 4(16):1081-1088.

DOI: https://doi.org/10.1007/s00784-011-0594-z 
Adhesion of conventional and simplified resin-based luting cements to superficial and deep dentin

\section{Mutlu Özcan • Ayse Mese}

Mutlu Özcan

University of Zürich, Dental Materials Unit, Center for Dental and Oral Medicine, Clinic for Fixed and Removable Prosthodontics and Dental Materials Science, Plattenstrasse 11, $\mathrm{CH}-8032$, Zürich, Switzerland

e-mail: mutluozcan@hotmail.com

Ayse Mese

Dicle University, School of Dentistry, Department of Prosthodontics, Diyarbakır, Turkey

Short title: Adhesion of cements to superficial and deep dentin

\section{Corresponding to:}

Prof. Dr.med.dent. Mutlu Özcan, Ph.D University of Zürich

Head of Dental Materials Unit

Center for Dental and Oral Medicine

Clinic for Fixed and Removable Prosthodontics and Dental Materials Science

Plattenstrasse 11

$\mathrm{CH}-8032$, Zürich, Switzerland

Tel: $+41-44-6345600$

Fax: +41-44-6344305

e-mail: mutluozcan@hotmail.com 


\section{Abstract}

Objectives: This study evaluated the bond strengths of conventional (chemically- and dualpolymerized) and simplified resin-based luting cements with their corresponding adhesives, to superficial dentin (SD) and deep dentin (DD). Materials and Methods: Recently extracted third molars ( $N=70, n=10$ per group) were obtained and prepared for testing procedures. After using their corresponding etchants, primers and/or adhesive systems, the conventional and simplified cements (Variolink II [Group A, conventional], Bifix QM [Group B, conventional], Panavia F2.0 [Group C, conventional], Multilink Automix [Group D, simplified], Superbond C\&B [Group E, conventional], Clearfil Esthetic Cement [Group F, simplified], Ketac-Fil [Group G, conventional]) were adhered incrementally onto the dentin surfaces using polyethylene molds (inner diameter: $3.5 \mathrm{~mm}$, height: $5 \mathrm{~mm}$ ) and polymerized accordingly. Resin-modified glass-ionomer cement (RMGIC) acted as the control material. Shear bond strengths $(1 \mathrm{~mm} / \mathrm{min})$ were determined after 500 times of thermocycling. Kruskal-Wallis and Mann-Whitney tests were_used to analyze the data $(\alpha=0.05)$. Results: Bond strength (MPa) results were significantly affected by the cement types and their corresponding adhesive systems $(p<0.05)$. The

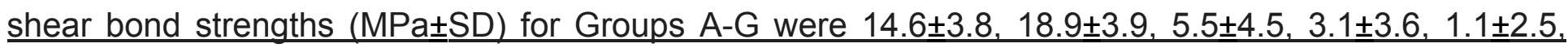
$15.5 \pm 2.6,7 \pm 4.3$ and $7.1 \pm 5.8,15.1 \pm 7.8,8.4 \pm 7.3,7.5 \pm 7.3,4.9 \pm 5.1,12.5 \pm 2.1,6 \pm 2.6$ for SD and DD, respectively. The level of dentin depth did not decrease the bond strength significantly $(p>0.05)$ for all cements, except for Variolink II ( $p<0.05)$. Conclusions: On the SD, bond strength of resin cements with "etch-and-rinse" adhesive systems (Variolink II, Bifix QM, Super-Bond C\&B) showed similar results being higher than those of the simplified ones.

Clinical Relevance: Simplified cements and RMGIC as control material showed inferior adhesion to superficial and deep dentin compared to conventional resin cements tested.

Keywords Dentin $\bullet$ Self-adhesive cements $\bullet$ Shear bond strength $\bullet$ Resin luting cement 


\section{Introduction}

The longevity of indirect fixed-dental-prostheses (FDP) could be affected by multiple factors including the cementation mode that is basically the final stage of consecutive clinical procedures. In principle, the primary function of the cementation is to establish reliable retention of the FDP, a durable seal of the space between the tooth and the restoration, and to provide adequate optical properties especially for ceramic or polymeric FDPs [1]. Today, adhesive properties of dental cements are of importance as it enables clinicians to perform minimal invasive restorations.

At present, dental cements are divided into two groups: water-based cements and polymerizing resin-based cements. Conventional dental cements such as zinc polycarboxylate and glass-ionomer cements $(\mathrm{GIC})$ are based on polyacids such as polyalkenoate that set as the result of acid-base reaction within an aqueous environment [2,3] and yield to lower adhesion to dental tissues [4]. Resinmodified glass-ionomer cements (RMGICs) containing hydrophilic monomers on the other hand, rely on the formation of a methacrylate-based network to augment the ionic cement structure through either grafting polymerizable double bonds onto a polyalkenoate backbone or by the incorporation of free radically polymerizable methacrylate monomers in the cement composition [5]. RMGICs are able to bond to dental tissues through the acidic functional groups capable of chelation with the calcium in hydroxyapatite [6]. As opposed to water-based cements and RMGICs, resin cements present negligible solubility, improved retention, better seal of the margins and significantly improved aesthetic properties [7-10]. Additionally, survival rates of FDPs cemented with polymerizing cements are reported to be better than with water-based cements [1].

Adhesive properties of resin cements are generally dictated by the adhesive systems used to condition the dental tissues. Until recently, resin cements were divided into three subgroups according to the adhesive system used to prepare the tooth prior to cementation. The so-called chemical- or 
photo-polymerized conventional resin cements often utilize etch-and-rinse adhesive systems. In the other group, enamel and dentin are conditioned either using self-etching primers (simplified resin cements) or no conditioning of the tooth surface is required (self-adhesive resin cements). These materials were designed with the intent to simplify the cementation procedures while achieving also some degree of adhesion $[11,12]$.

Resin cements, be it conventional or simplified, may perform differently depending on their adhesive systems, since the latter is primarily in contact with the dentin. Contemporary adhesive systems used in dentistry interact with the enamel/dentin substrate either by removing the smear layer (etch-and-rinse technique) or by partially dissolving the smear layer, penetrating through it, decalcifying underlying intertubular dentin, and impregnating any remaining smear layer for the bonding (self-etch technique) [13]. While the etch-and-rinse bonding technique initiates by a separate etching step using $35-37 \%$ phosphoric acid that is later rinsed away, the self-etch/primer agent containing acidic monomers is only air-dried, thus remaining within the modified smear layer. The self-etch approach could also be called as "etch-and-dry" approach [14]. Such adhesives make the application less technique-sensitive for the clinicians [15]. Besides micromechanical interlocking through hybridization, specific functional monomers of 'mild' or 'intermediate' two-step self-etching adhesives were shown to interact chemically with residual hydroxyapatite crystals that remain available in the submicron hybrid layer [16]. While some studies reported higher bond strengths to dentin with two-step self-etching adhesives compared to one-step ones [17-19], others reported comparable [20] or lower bonding efficacy to dentin [21,22]. In fact, testing resin cements with their adhesives/primers after aging conditions would deliver more realistic results [23]. It can be anticipated that due to the acidic nature of the self-etch adhesives and their permeability [24], after aging conditions in aqueous media, adhesion of simplified resin cements could be compromised. 
Resin-bonded FDPs are usually bonded to enamel or superficial dentin (SD). However, full-coverage FDPs or extensive overlays are cemented to deep dentin (DD) since such restorations require more room for the restorative material. In previous studies, bond strengths of resin composites to dental tissues were found to be higher in SD than in DD [25-28]. Since SD contains more intertubular dentin area and it is rich in collagen fibrils, it makes adhesion with resin-based materials favourable [9]. However, impaired adhesion could be expected on DD due to higher water content compared to SD [23]. Yet, this aspect was not studied for resin-based luting cements to date.

Therefore, the objective of this study was to evaluate the bond strength of conventional and simplified resin-based luting cements together with their adhesive/primer systems to SD and DD. The hypotheses tested were that a) adhesion to DD would be lower than to SD and b) resin cements having "etch and rinse" adhesive systems would deliver higher results than those of the simplified cements that are used in combination with self-etching adhesives.

\section{Materials and Methods}

This study comprised 8 cements of which 5 were conventional, 2 simplified resin-based and 1 resinmodified glass-ionomer cements. Adhesive potential of these cements on SD and DD of third molar teeth was tested. The cements used in this study and the specific differences between the products

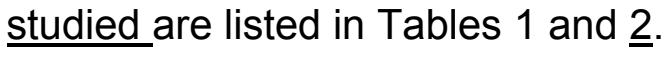

Third molars $(\mathrm{N}=70)$ stored in distilled water with 0.1 percent thymol solution at room temperature were selected from a pool of recently extracted teeth. In order to determine that the enamel was free of caries, the exact location of cusp tips, enamel, dentin and pulp horns of the teeth, initially one X-ray was taken. 
The teeth were embedded using polymethylmethacrylate (PMMA, Condular AG, Wager, Switzerland) with their occlusal surfaces exposed in polyethylene rings (diameter: $10 \mathrm{~mm}$, height: 12 $\mathrm{mm})$. The apices of the teeth were shortened when they were longer than $10 \mathrm{~mm}$.

Then, the cusps of the molars were removed in a trimmer (Isomet, Buehler Ltd., Lake Bluff, IL, USA) under water-cooling until flat dentin surfaces were achieved. Dentin level after removal of cusp tips was considered as SD group. One $\mathrm{mm}$ below the SD level was indicated and considered as DD [9]. Only the specimens were included in the tests when dentin level and the highest point of the pulp horn was at least $1 \mathrm{~mm}$ (Fig. 1). The other specimens were discarded. In total 2 X-rays were taken from each specimen.

In both SD and DD groups, flat dentin surfaces were polished with 400 grit silicon carbide papers (English Abrasives Ltd, London, England) under water-cooling and then rinsed thoroughly in order to create bonding surfaces covered with smear layers [29]. Subsequently, bonding procedures were carried out.

While for the conventional resin cements, the corresponding manufacturer's etchant, primer and/or adhesive system was used, for the simplified cements the corresponding manufacturer's primer was used. Resin-modified glass-ionomer acted as the control group (Table 3). After conditioning the dentin surfaces, the cements were adhered incrementally with a hand instrument on the dentin surfaces using polyethylene moulds (inner diameter: $3.5 \mathrm{~mm}$, height: $5 \mathrm{~mm}$ ) (Fig. 2a). The mould was removed gently after the cement was polymerized (Fig. 2b). The specimens were kept at $37^{\circ} \mathrm{C}$ for 24 hours and then aged in a thermocycling device (Willytec, Gräfelfing, Germany) between $5-55^{\circ} \mathrm{C}$ for 500 times (dwell time: $30 \mathrm{~s}$, transfer time from one bath to the other: $5 \mathrm{~s}$ ). The teeth were maintained wet at all times during all procedures except during X-rays. 
Specimens were then mounted in the apparatus of the Universal Testing Machine (Zwick ROELL Z2.5 MA 18-1-3/7, Ulm, Germany) and the force was applied to the adhesive interface until failure occurred. The load was applied with a $50 \mathrm{kgf}$ load cell to the substrate-adherend interface using a shearing blade with a 45-degree inclination at the tip, at a crosshead speed of $1 \mathrm{~mm} / \mathrm{min}$ and the stress-

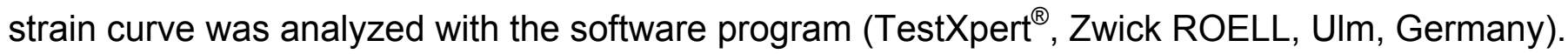

Statistical analysis was performed using SPSS 11.0 software for Windows (SPSS Inc., Chicago, IL, USA). When significant differences were found between or within groups, Scheffé $F$ test was used to determine the differences. Because the data for bond strength was not normally distributed according to Levene test, Kruskal-Wallis and Mann-Whitney non-parametric tests were used. P values less than 0.05 were considered to be statistically significant in all tests. Spontaneous debondings during thermocycling was considered as $0 \mathrm{MPa}$.

\section{Results}

The mean bond strength values for the tested cements at two levels of dentin are presented in Table 4.

During thermocycling, Clearfil Esthetic Cement group had 2, Multilink Automix, Panavia F 2.0, Bifix QM, Super-Bond C\&B and Ketac-Fil had 1 spontaneous debondings. These specimens were considered as $0 \mathrm{MPa}$.

While resin cement type had a significant effect on the bond strength results $(p<0.05)$, the level of dentin did not affect the results significantly $(p>0.05)$.

On the superficial dentin, Variolink II, Bifix QM and Super-Bond C\&B showed significantly higher bond results than those of other cements $(p<0.05)$. Within individual cement groups, all cements except Variolink II $(p<0.05)$, showed no significant difference between SD and DD $(p>0.05)$. 
On the DD, Bifix QM and Super-Bond C\&B showed significantly higher bond results than those of other cements $(p<0.05)$ being not significant from one another $(p>0.05)$.

\section{Discussion}

This study compared the adhesion of different conventional and simplified resin cements with their corresponding adhesives/primers on SD and DD. Since the level of dentin depth did not affect the results except for Variolink II, the first hypothesis could be partially accepted. Resin cements having "etch and rinse" adhesive systems (Variolink II, Bifix QM and Super-Bond C\&B) delivered significantly higher results than those of other cements tested. Hence, the second hypothesis could be accepted. One possible explanation for the differential behaviour of Variolink II on both SD and DD may stem from the composition and nature of its water-based primer, Syntac. In this system, the dentin surface remains in a moist state that prevents the collapse of unsupported collagen and promote primer-resin infiltration [30]. Reis and others [30] have demonstrated that the moisture degree of dentin was effective on the bond strength of luting systems. By monitoring the amount of water used to rewet air-dried dentin surface, they showed that etch-and-rinse adhesive systems achieve optimal bond strengths at different moisture degrees that is usually depended on the solvent present in each system. Their data confirmed in a quantitative manner, indicated that water-based systems require a rather drier dentin surface while acetone-based systems require a rather wetter dentin surface for improved bond strengths.

Since etching dentin separately would result in higher interaction with dentin and due to their lower hydrophilicity, it can be stated that "etch and rinse" adhesive systems compensate for other factors and lead to higher bond strength of the resin cements to dentin [31]. The "etch and rinse" adhesives require a moist substrate for optimal bonding [32], making it highly sensitive since the collapse of over-dried, exposed collagen acts as a difficult substrate for the monomer infiltration. However, this also indicates 
that in the case of increased dentin wetness, which occurs when dentin depth increases, an overly wet condition may be created [33]. This makes 3-step "etch and rinse" adhesives more technique sensitive compared to self-etch adhesive types. That however did not affect our findings, as the operator was careful in maintaining ideal bonding conditions for the adhesive. Thus, the results of our study suggest that when wet technique is meticulously followed, SD is a favourable substrate for the "etch and rinse" system. In the DD, similar observations were made in this study except for Variolink II. The components of this cement had to be mixed by hand. This technique is more sensitive than using dispenser syringes which could be one of the reasons for lower results [34]. On the other hand, although Super-Bond C\&B was also hand mixed, superior results were obtained on both SD and DD. This could be attributed to better degree of conversion in this chemically polymerized cement compared to photo-polymerized ones [35].

The etching duration and etching agents showed variations among the materials tested. The etching medium was in three of the cements $37-40 \% \mathrm{H}_{3} \mathrm{PO}_{4}$ (Variolink II, Bifix QM, Panavia F 2.0) except for Super-Bond C\&B where 10\% citric acid- $3 \%$ ferric chloride (10-3) was used. It has been previously reported that a 4- META/MMA resin, when initiated with oxidized tri-n-butylborane (TBBO), provides excellent adhesion to dentin when the dentin surface is pre-treated with citric acid solution containing ferric chloride [36]. Ferric ions play a role in stabilizing dentin collagen during acid conditioning [36]. The bond strength between dentin and MMA resin was significantly improved with the combination of ferric chloride adsorbed onto dentin and TBBO $[36,37]$. Furthermore, when the polymerization initiates at the dentin-resin interface, polymerization shrinkage can be minimized resulting in better adhesion.

The self-etching primers eliminate the technique-sensitive rinsing step to remove the phosphoric acid from dentin. However, the most efficient self-etching adhesives are based on strongly acidic adhesive monomers. Most of the currently available self-etching adhesives are methacrylate-based with a pH- 
value in the range of 1.5-2.5. Under these strong acidic conditions, esters such as triethyleneglycol dimethacrylate (TEGDMA) as in Clearfil Eshetic cement and methacryloyloxydecyl dihydrogen phosphate (MDP) as in Panavia F 2.0 are hydrolytically degraded [38]. The degradation of the adhesive influences the bond strength negatively. This may explain the lower bond strengths for simplified resin cements (Mutlilink Automix and Clearfil Esthetic Cement) used in this study. Also, storage conditions of self-etch adhesives have been reported to have an influence on the performance of such materials [39]. Such materials are recommended to be stored cold or at least below $20^{\circ} \mathrm{C}$. The materials have been used in this study within 3 months upon delivery from manufacturers. They all had expiry dates of at least one more year when the experiments were commenced. They were kept in a fridge at $6^{\circ} \mathrm{C}$ and were brought to the room temperature prior to the experiments. Therefore, this parameter is not expected to have an influence on the results. This however may not apply to materials other than those studied in this study.

Bonding to DD has been expected to be more challenging than to SD mainly due to the reduced area of solid intertubular dentin associated with the increased water content. One recent study indicated that tubular density and tubular cross-sectional area were in fact not significantly different in deep and coronal dentin [40]. This could be one reason for the insignificant differences between SD and DD. It should however be noted that the pulpal pressure was not simulated in this study. Positive intrapulpal pressure has been regarded to as detrimental to the bonding process [41]. The presence of pulpal fluid under pressure in vital dentin could be an important factor influencing adhesive bonding to dentin. In the case of simulation of intrapulpal pressure, confocal laser scanning microscopy examination revealed a distinctly shallower penetration of the adhesives into dentin compared to the specimens treated without intrapulpal pressure [42]. Nevertheless, although technically pulpal pressure simulation is not easy, 
future studies may consider the impact of this aspect on the adhesion of resin cements in especially in deep dentin.

In order to simulate the clinical aging factor all specimens were thermocycled in this study. Thermal stresses generate stresses due to differences in the coefficient of thermal expansions of the cement and can result in bond failure at the tooth-restorative interface [43]. Another possibility for the decrease in bond strength after thermocycling could be attributed to increased water absorption or solubility of the composite, or both. Not all studies support these outcomes [43]. The results of this study at least for Panavia F 2.0 and Superbond C\&B was lower than a previous study (29 to $31 \mathrm{MPa}$ for SD and 10 to 18 $\mathrm{MPa}$ for DD, respectively) where tensile test was used and no thermocycling was practiced [9]. $\underline{\text { In that }}$ study, even though Panavia F 2.0 was polymerized in the self-curing mode, the results were higher than this study. In another study by Melo et al. microtensile test method was used to study the bond strength of Panavia F 2.0 and Multilink Automix to dentin in their dual-polymerized versions in combination with either self-etching adhesive system or three-step etch-and-rinse adhesive system [31]. Although only $\underline{\text { superficial dentin was used in that study and no aging regimens were practiced, both cements delivered }}$ significantly higher results with the three-step etch-and-rinse adhesive system (Panavia F 2.0: 34.4 MPa; Multilink Automix: $33 \mathrm{MPa}$ ). The results with both three-step etch-and-rinse adhesive system and self-etching adhesive systems were also considerably higher than those of the results obtained from SD group in this study. In the study of Melo et al. [31], Multilink Automix cement in combination with selfetching adhesive presented more than $50 \%$ pre-test failures. These were not considered as $0 \mathrm{MPa}$, which might be explained why the results were also high with this cement. The discrepancy in the results of these studies and those of this study could therefore be attributed to the differences in the test methods. Tensile bond strength tests tend to deliver higher results compared to shear test [44]. 
Effect of prolonged thermocycling could be studied in the future but already after short-term thermocycling, lower results were obtained with the simplified resin cements. During thermocycling process, with some cement systems further polymerization and thereby increased degree of conversion could be observed. For this reason, short and long-term thermocycling in the same study may bring additional information on the conversion behaviour of such cements.

It should also be noted that in this study, spontaneous debondings during thermocycling were considered as $0 \mathrm{MPa}$. Such failures may have various origins. They can be either as a result of either cement adhesion failures or technical failures. When the cement does not wet the substrate surface properly, some unadhered areas could be observed which may initiate the failure. In our laboratory protocol, after debonding, the adhered surfaces are evaluated for a possible defect. When the adhered surfaces of the cements were evaluated, in none of the cases any air-bubbles were obserded.

From the clinical point of view, the depth of dentin could not be controlled during tooth preparation. Therefore, clinically the cements that adhere well both to SD and DD should be of choice. In this study, at least $1 \mathrm{~mm}$ was maintained between the DD and the pulp horns. The variations in this distance may affect the results. In this study, flat dentin surfaces were polished with 400 grit silicon carbide papers under water-cooling and then rinsed thoroughly in order to create bonding surfaces covered with smear layers [29] but 600 grit silicon carbide papers may modify the smear layer similar to tooth cutting and affect the results [45].

Different tests can be used to define adhesive strength on dentin. The results of this study can be used for screening purposes but further studies using micro-tensile test method need to verify the findings of this study. In-vitro studies on adhesion tests present some limitations since the cements are directly polymerized without considering the presence of pulpal pressure, cementation pressure, 
thickness of the crown and light transmission of the material of the crowns. Nevertheless, in-vitro studies still do serve for ranking the materials within one study.

\section{Conclusions}

Within the limitations of the present research, the following can be concluded:

1- On the superficial dentin, bond strength of the tested cements showed more favourable results when their corresponding adhesive system was based on "etch-and-rinse" system (Variolink II, Bifix QM) $(p<0.05)$. Chemically polymerized cement, Super-Bond C\&B also showed similar results with Variolink II, Bifix QM (p>0.05).

2- Simplified resin cements and resin-modified glass-ionomer cement showed the lowest results being not significant from one another $(p>0.05)$.

3- On both superficial and deep dentin, dual-polymerized Bifix QM and chemically polymerized SuperBond C\&B performed equally well ( $p>0.05)$.

\section{Acknowledgements}

The authors express their gratitude to Sun Medical, Tokyo, Japan, Ivoclar Vivadent, Schaan, Liechtenstein, Voco, Cuxhaven, Germany, Kuraray Medical Inc, Kurashiki, Japan, for generous provision of the cements.

\section{Conflict of Interest}

The authors declare that they have no conflict of interest. 


\section{References}

1. Edelhoff D, Özcan M (2007) To what extend does the longevity of fixed dental prostheses depend on the function of cement? Clin Oral Implants Res 18:193-204.

2. Smith DC (1968) A new dental cement. Br Dent J 124:381-384.

3. Wilson AD, Kent BE (1971) The glass ionomer cement: a new translucent dental filling material. J Appl Chem Biotechnol 21:313-320.

4. Mitra SB (1991) Adhesion to dentin and physical properties of a light-cured glass-ionomer liner / base. J Dent Res 70:72-77.

5. Antonucci JM (1987) Formulation and evaluation of resin modified glass ionomer cements. Trans Soc Biomater 13:225.

6. Fu BP, Sun XM, Qian WX, Shen YQ, Chen RR, Hannig M (2005) Evidence of chemical bonding to hydroxyapatite by phosphoric acid esters. Biomaterials 26:5104-5110.

7. Mathis Mathis RS, Ferracane JL (1989) Properties of a glass-ionomer / resin-composite hybrid material. Dent Mater 5:355-358.

8. Rosenstiel SF, Land MF, Crispin BJ (1998) Dental luting agents: A review of the current literature. J Prosthet Dent 80:280-301.

9. Yang B, Ludwig K, Adelung R, Kern M (2006) Micro-tensile bond strength of three luting resins to human regional dentin. Dent Mater 22:45-56.

10. Hill EE (2007) Dental cements for definitive luting: a review and practical clinical considerations. Dent Clin North Am 51:643-658.

11. Radovic I, Monticelli F, Goracci C, Vulicevic ZR, Ferrari M (2008) Self-adhesive resin cements: a literature review. J Adhes Dent 10:251-258. 
12. Ferracane JL, Stansbury JW, Burke FJT (2010) Self-adhesive resin cements- chemistry, properties and clinical considerations. J Oral Rehabil 1-20 [Epub ahead]

13. Van Meerbeek B, Vargas M, Inoue S, Yoshida Y, Peumans M, Lambrechts P, Vanherle G (2001) Adhesives and cements to pro- mote preservation dentistry. Oper Dent (Suppl 6):119-144.

14. Van Meerbeek B, De Munk J, Yoshida Y, Inoue S, Vargas M, Vijay P, Van Landuyt K, Lambrechts P, Vanherle G (2003) Adhesion to enamel and dentin: Current status and future challenges. Oper Dent 28:215-235.

15. Tay FR, Pashley DH (2001) Aggressiveness of contemporary self- etching systems 1: Depth of penetration beyond smear layers. Dent Mater 17:296-308.

16. Tay F, Pashley D, Yoshiyama M (2002) Two modes of nanoleakage expression in single-step adhesives. J Dent Res 81:47-476.

17. Armstrong SR, Vargas MA, Fang Q, Laffoon JE (2003) Microtensile bond strength of a total-etch 3step, total-etch 2-step, self-etch 2-step, and a self-etch 1-step dentin bonding system through 15-month water storage. J Adhes Dent 5:47-56.

18. Yoshida Y, Nagakane K, Fukuda R, Nakayama Y, Okazaki M, Shintani H, Inoue S, Tagawa Y, Suzuki K, De Munck J, Van Meerbeek B (2004) Comparative study on adhesive perform- ance of functional monomers. J Dent Res 83:454-458.

19. Sensi L, Lopes G, Monteiro S, Baratieri L, Vieira L (2005) Dentin bond strength of self-etching primers/adhesives. Oper Dent 30:63-68.

20. Tay FR, Pashley DH, Suh BI, Carvalho RM, Itthagarun A (2002) Single-step adhesives are permeable membranes. J Dent 30:371-382.

21. Cheong C, King NM, Pashley DH, Ferrari M, Toledano M, Tay FR (2003) Incompatibility of self-etch adhesives with chemical/dual-cured composites: two-step vs one-step systems. Oper Dent 28:747-755. 
22. Bolhuis PB, de Gee AJ, Kleverlaan CJ, El Zohairy AA, Feilzer AJ (2006) Contraction stress and bond strength to dentin for compatible and incompatible combinations of bonding systems and chemical and light-cured core build-up resin composites. Dent Mater 22:223-233.

23. Gale MS, Darvell BW (1999) Thermal cycling procedures for laboratory testing of dental restorations. J Dent 27:89-99.

24. Suh BI, Feng L, Pashley DH, Tay FR (2003) Factors contributing to the incompatibility between simplified-step adhesives and chemically cured or dual-cured composites. Part III. Effect of acidic resin monomers. J Adhes Dent 5:267-282.

25. Shono Y, Ogawa T, Terashita M, Carvalho RM, Pashley EL, Pashley DH (1999) Regional measurement of resin-dentin bonding as an array. J Dent Res 78:699-705.

26. Akawa H, Nikaido T, Takada T, Burrow MF, Tagami J (2002) Shear bond strengths to coronal and pulp chamber floor dentin. Am J Dent 15:383-388.

27. Takahashi A, Sato Y, Uno S, Pereira PNR, Sano H (2002) Effects of mechanical properties of adhesive resins on bond strength to dentin. Dent Mater 18:263-268.

28. Lopes GC, Perdigão J, Lopes Mde F, Vieira LC, Baratieri LN, Monteiro S Jr (2006) Dentin Bond strengths of simplified adhesives: effect of dentin depth. Compend Contin Educ Dent 27:340-346.

29. De Munck J, Vargas M, Iracki J, Van Landuyt K, Poitevin A, Lambrechts P, Van Meerbeek B (2005) One-day bonding effectiveness of new self-etch adhesives to bur-cut enamel and dentin. Oper Dent 30:39-49.

30. Reis A, Loguercio AD, Azevedo CLN, Carvalho RM, Singer JM, Grande RHM (2003) Moisture spectrum of demineralized dentin for different solvent-based adhesive system. J Adhes Dent 5:183-192. 
31. Marques Melo R, Özcan M, Barbosa SH, Galhano G, Amaral R, Bottino MA, Valandro LF (2010). Bond strength of two resin cements on dentin using different cementation strategies. J Esthet Restor Dent 22:262-268.

32. Carvalho RM, Pegoraro TA, Tay FR, Pegoraro LF, Silva NRFA, Pashley DH (2004) Adhesive permeability affects coupling of resin cements that utilize self-etching primers to dentine. J Dent 32:5565.

33. Paul SJ, Leach M, Rueggeberg FA, Pashley DH (1999) Effect of water content on the physical properties of model dentine primer and bonding resins. J Dent 27:209-214.

34. de Gee AJ, ten Harkel HC, Davidson CL (1989) The influence of mixing ratio on the working time, strength and wear of composites. Aust Dent J 34:466-469.

35. Kinomoto Y, Torii M, Takeshige F, Ebisu S (1999) Comparison of polymerization contraction stresses between self- and light-curing composites. J Dent 27:383-389.

36. Nakabayashi N, Kojima K, Masuhara E (1982) The promotion of adhesion by the infiltration of monomers into tooth substrates. J Biomed Mater Res 16:265-273.

37. Takagaki T, Nikaido T, Tsuchiya S, Ikeda M, Foxton RM, Tagami J (2009) Effect of hybridization on bond strength and adhesive interface after acid-base challenge using 4-META/MMA-TBB resin. Dent Mater J 28:185-193.

38. Moszner N, Salz U, Zimmermann J (2005) Chemical aspects of self-etching enamel-dentin adhesives; a systematic review. Dent Mater 21:895-910.

39. Ma S, Nakajima KF, Nishiyama N (2009) Effects of storage temperature on the shelf life of one-step and two-step self-etch adhesives. Oper Dent 34:472-480.

40. Caiado AC, de Goes MF, de Souza-Filho FJ, Rueggeberg FA (2010) The effect of acid etchant type and dentin location on tubular density and dimension. J Prosthet Dent 103:352-361. 
41. Sengun A, Ozturk B, Ozer F (2003) The effect of simulated intrapulpal pressure on bond strength to enamel and dentine. J Oral Rehabil 30:550-555.

42. Pioch T, Staehle HJ, Schneider H, Duschner H, Dorfer CE (2001) Effect of intrapulpal pressure simulation in vitro on shear bond strengths and hybrid layer formation. Am J Dent 14:319-323.

43. El-Araby AM, Talic YF (2007) The effect of thermocycling on the adhesion of self-etching adhesives on dental enamel and dentin. J Contemp Dent Pract 8:17-24.

44. Valandro LF, Özcan M, Amaral R, Vanderlei A, Bottino MA (2008) Effect of testing methods on the bond strength of resin to zirconia-alumina ceramic: Microtensile versus shear test. Dent Mater J 27:849855.

45. Tay FR, Carvalho R, Sano H, Pashley DH (2000) Effect of smear layers on the bonding of a selfetching primer to dentin. J Adhes Dent 2:99-116. 


\section{Figure legends:}

\section{Tables}

Table 1 Brand names, manufacturers, chemical composition and batch numbers of the resin cements tested

Table 2 Specific differences between the tested cement systems

Table 3 Cementation protocols of the resin cements tested

Table 4 Mean and standard deviations (SD) of the bond strength results (MPa) on superficial dentin (SD) and deep dentin (DD). Same upper case small letters indicate no significant difference in a column and same capital letters indicate no significant difference in a row $(p>0.05)$

\section{Figures}

Fig. 1 Sketch of the position of superficial and deep dentin in relation to the cusp tips and pulp. Note that $1 \mathrm{~mm}$ below superficial dentin was considered as deep dentin. With X-rays it was made sure that dentin was available at least $1 \mathrm{~mm}$ above the pulp horns

Figs. 2a-b a) Cement was applied incrementally in the polyethylene molds, not exceeding $2 \mathrm{~mm}$, and polymerized accordingly. b) Bonded cement on the dentin surface after removal of the mold 
Tables:

Table 1 Brand names, manufacturers, chemical composition and batch numbers of the resin cements tested

\begin{tabular}{|c|c|c|c|}
\hline Material & Manufacturer & Chemical composition* & $\begin{array}{l}\text { Batch } \\
\text { number }\end{array}$ \\
\hline Variolink II & $\begin{array}{l}\text { Ivoclar Vivadent, } \\
\text { Schaan, } \\
\text { Liechtenstein }\end{array}$ & $\begin{array}{l}\text { Monomer Matrix: Bis-GMA, UDMA, TEGDMA } \\
\text { Inorganic Fillers: Barium Glass, Ytterbium } \\
\text { Trifluoride, Ba-Al-fluorosilicate glass, Spheroid } \\
\text { mixed oxide } \\
\text { Catalyst, stabilizers, pigments }\end{array}$ & J17818 \\
\hline Bifix QM & $\begin{array}{l}\text { Voco, } \\
\text { Cuxhaven, } \\
\text { Gemany }\end{array}$ & $\begin{array}{l}\text { Monomer Matrix: Bis-GMA } \\
\text { Inorganic Fillers }\end{array}$ & 1217E1 \\
\hline Panavia F2.0 & $\begin{array}{l}\text { Kuraray Medical } \\
\text { Inc, } \\
\text { Kurashiki, Japan }\end{array}$ & $\begin{array}{l}\text { Monomer Matrix: MDP, bisphenol-A polyethoxy } \\
\text { dimethacrylate } \\
\text { Inorganic Fillers: silanated barium glass, silanated } \\
\text { titanium oxide, sodiumfluoride, colloidal silica }\end{array}$ & 41190 \\
\hline $\begin{array}{l}\text { Multilink } \\
\text { Automix }\end{array}$ & $\begin{array}{l}\text { Ivoclar Vivadent, } \\
\text { Schaan, } \\
\text { Liechtenstein }\end{array}$ & $\begin{array}{l}\text { Monomer Matrix: Ethoxilated Bis-EMA, UDMA, Bis- } \\
\text { GMA, HEMA } \\
\text { Inorganic Fillers: Barium, Glass, Ytterbium } \\
\text { Trifluoride, Spheroid mixed oxide }\end{array}$ & G10444 \\
\hline $\begin{array}{l}\text { Clearfil } \\
\text { Esthetic } \\
\text { Cement }\end{array}$ & $\begin{array}{l}\text { Kuraray Medical } \\
\text { Inc, } \\
\text { Kurashiki, Japan }\end{array}$ & $\begin{array}{l}\text { Monomer Matrix: Bis-GMA, TEGDMA, other } \\
\text { methacrylate monomers } \\
\text { Inorganic Fillers: silanated glass fiber, silanated } \\
\text { silica, colloidal silica } \\
\text { Benzoyl peroxide, dl Camphorquinone, pigments }\end{array}$ & 41115 \\
\hline $\begin{array}{l}\text { Superbond } \\
\text { C\&B }\end{array}$ & $\begin{array}{l}\text { Sun Medical, } \\
\text { Tokyo, Japan }\end{array}$ & $\begin{array}{l}\text { Monomer Matrix : 4-META, MMA, PMMA } \\
\text { Inorganic Fillers, } \\
\text { TBB, hydrocarbon, pigments }\end{array}$ & MT3 \\
\hline Ketac-Fil & $\begin{array}{l}\text { 3M ESPE, Seefeld, } \\
\text { Germany }\end{array}$ & $\begin{array}{l}\text { Polyacids and calcium fluoroaluminosilicate glass } \\
\text { powder }\end{array}$ & 268054 \\
\hline
\end{tabular}

Bis-GMA: Bisphenol A glycol dimethacrylate; TEGDMA: Triethylene glycol dimethacrylate; Bis-EMA: Ethoxylated bisphenol A glycol dimethacrylate; UDMA: Urethane dimethacrylate; HEMA: Hydroxyethyl methacrylate; MMA: Methylmethacrylate; PMMA: Polymethylmethacrylate; MDP: 10-methacryloyloxidecyldihydrogen-phosphate; TBB: Tri-n-butyl borane; 4-META: 4-methacryloxyethyl trimellitate anhydride. *Information according to each manufacturer's material safety sheet data. (Variolink II, Ivoclar Vivadent: 01.10.2007, Nr.1194; Bifix QM, Voco, 25.03.2007, Nr.1907; Panavia F2.0, Kuraray Medical, 09.30.2008, Nr.US089-PA; Multilink Automix, Ivoclar Vivadent: 01.10.2007, Nr.1582; Clearfil Esthetic Cement, Kuraray Medical, 13.11.2008, Nr.1582; Superbond C\&B, Sun Medical, 24.04.2007, Nr.sb03; Ketac-Fil, 3M ESPE, 05.10.2007; Nr.1907). 


\begin{tabular}{|l|l|l|}
\hline $\begin{array}{l}\text { Cement } \\
\text { Variolink II }\end{array}$ & Cement Type / Curing System & Cement Bonding System \\
\hline Bifix QM & Conventional adhesive / Dual-polymerized & 3-step etch-and-rinse \\
\hline Panavia F2.0 & Conventional adhesive / Dual-polymerized & 3-step etch-and-rinse \\
\hline Multilink Automix & Conventional adhesive / Dual-polymerized & Self-etch \\
\hline Clearfil Esthetic Cement & Simplified / Dual-polymerized & Self-etch \\
\hline Superbond C\&B & Simplified / Dual-polymerized & Self-etch \\
\hline Ketac-Fil & Auto-polymerized & None \\
\hline & Resin-modified Glass-ionomer / & None \\
\hline
\end{tabular}

Table 2 Specific differences between the tested cement systems 


\begin{tabular}{|c|c|c|c|c|}
\hline Cements & Etching & Priming/Bonding & Cement & Polymerization \\
\hline Variolink II & $\begin{array}{l}37 \% \mathrm{H}_{3} \mathrm{PO}_{4} \\
10-15 \mathrm{~s}+ \\
\text { rinsing + drying }\end{array}$ & $\begin{array}{l}\text {-Syntac Primer } 15 \mathrm{~s} \\
\text {-Syntac Adhesive } 10 \mathrm{~s} \\
\text { - Heliobond }\end{array}$ & $\begin{array}{l}\text { Mix base and catalyst } \\
(1: 1)\end{array}$ & $\begin{array}{l}40 \mathrm{~s} \\
\text { photo- } \\
\text { polymerization }\end{array}$ \\
\hline Bifix QM & $\begin{array}{l}37 \% \mathrm{H}_{3} \mathrm{PO}_{4} \\
\text { (Voco acid } \\
\text { etching gel) } \\
\text { max. } 15 \mathrm{~s}+ \\
\text { rinsing + drying }\end{array}$ & $\begin{array}{l}\text { Solobond Plus } \\
\text { - Primer } 30 \mathrm{~s} \text {, dry } \\
\text {-Adhesive } 20 \text { s photo- } \\
\text { polymerize }\end{array}$ & Dispenser syringe & $\begin{array}{l}20 \mathrm{~s} \\
\text { photo- } \\
\text { polymerization }\end{array}$ \\
\hline $\begin{array}{l}\text { Panavia F } \\
2.0\end{array}$ & $\begin{array}{l}40 \% \mathrm{H}_{3} \mathrm{PO}_{4} \\
\text { (K-etchant gel) } \\
10 \mathrm{~s}+\text { rinsing + } \\
\text { drying }\end{array}$ & $\begin{array}{l}\text { Mix ED Primer II (liquid } \\
\text { A and liquid B 1:1) } 30 \mathrm{~s} \text {, } \\
\text { dry }\end{array}$ & $\begin{array}{l}\text { Mix paste } A \text { and } \\
\text { paste } B(1: 1)\end{array}$ & $\begin{array}{l}20 \mathrm{~s} \\
\text { photo- } \\
\text { polymerization }\end{array}$ \\
\hline $\begin{array}{l}\text { Multilink } \\
\text { Automix }\end{array}$ & - & $\begin{array}{l}\text { Mix Multilink primer } \\
\text { (Primer A and Primer B } \\
1: 1) 15 \mathrm{~s} \text {, dry }\end{array}$ & Dispenser syringe & $5 \mathrm{~min}$ \\
\hline $\begin{array}{l}\text { Clearfil } \\
\text { Esthetic } \\
\text { Cement }\end{array}$ & - & $\begin{array}{l}\text { Mix ED Primer II (liquid } \\
\text { A and liquid B 1:1) } 30 \mathrm{~s} \text {, } \\
\text { dry }\end{array}$ & Dispenser syringe & $\begin{array}{l}20 \mathrm{~s} \\
\text { photo- } \\
\text { polymerization }\end{array}$ \\
\hline $\begin{array}{l}\text { Super-Bond } \\
\text { C\&B }\end{array}$ & $\begin{array}{l}\text { Green } \\
\text { Activator }(10 \% \\
\text { citric acid- } 3 \% \\
\text { ferric chloride } \\
(10-3)) \\
5-10 \text { s + } \\
\text { rinsing + drying }\end{array}$ & - & $\begin{array}{l}\text { Bulk-mix technique: } \\
\text { Mix activated liquid: } \\
\text { monomer + catalyst } \\
\text { V }(4: 1) \\
\text { Add polymer powder } \\
\text { ( } 4 \text { drops: } 1 \text { drop } \rightarrow \\
\text { small cup of } \\
\text { measuring spoon) }\end{array}$ & $8-10 \mathrm{~min}$ \\
\hline Ketac-Fil & $\begin{array}{l}\text { Surface } \\
\text { conditioning } \\
\text { with Ketac } \\
\text { Conditioner for } \\
\text { 30s + rinsing } \\
\text { 30s + drying }\end{array}$ & & $\begin{array}{l}\text { Activate the capsule } \\
\text { in an activator and } \\
\text { then in a mixer for } 15 \\
\text { s. }\end{array}$ & $5 \mathrm{~min}$ \\
\hline
\end{tabular}

Table 3 Cementation protocols of the resin cements tested 


\begin{tabular}{|l|l|l|}
\hline Cements & Superficial Dentin & Deep Dentin \\
\hline Variolink II & $14.6 \pm 3.8^{\mathrm{a}, \mathrm{A}}$ & $7.1 \pm 5.8^{\mathrm{b}, \mathrm{b}}$ \\
\hline Bifix QM & $18.9 \pm 3.9^{\mathrm{a}, \mathrm{A}}$ & $15.1 \pm 7.8^{\mathrm{a}, \mathrm{A}}$ \\
\hline Panavia F 2.0 & $5.5 \pm 4.5^{\mathrm{b}, \mathrm{A}}$ & $8.4 \pm 7.3^{\mathrm{b}, \mathrm{A}}$ \\
\hline $\begin{array}{l}\text { Multilink Automix } \\
\begin{array}{l}\text { Clearfil Esthetic } \\
\text { Cement }\end{array}\end{array}$ & $3.1 \pm 3.6^{\mathrm{b}, \mathrm{A}}$ & $7.5 \pm 7.3^{\mathrm{b}, \mathrm{A}}$ \\
\hline $\begin{array}{l}\text { Super-Bond C\&B } \\
\text { Ketac-Fil }\end{array}$ & $1.1 \pm 2.5^{\mathrm{b}, \mathrm{A}}$ & $4.9 \pm 5.1^{\mathrm{b}, \mathrm{A}}$ \\
\hline
\end{tabular}

Table 4 Mean and standard deviations (SD) of the bond strength results (MPa) on superficial dentin (SD) and deep dentin (DD). Same upper case small letters indicate no significant difference in a column and same capital letters indicate no significant difference in a row $(p>0.05)$ 


\section{Figures:}

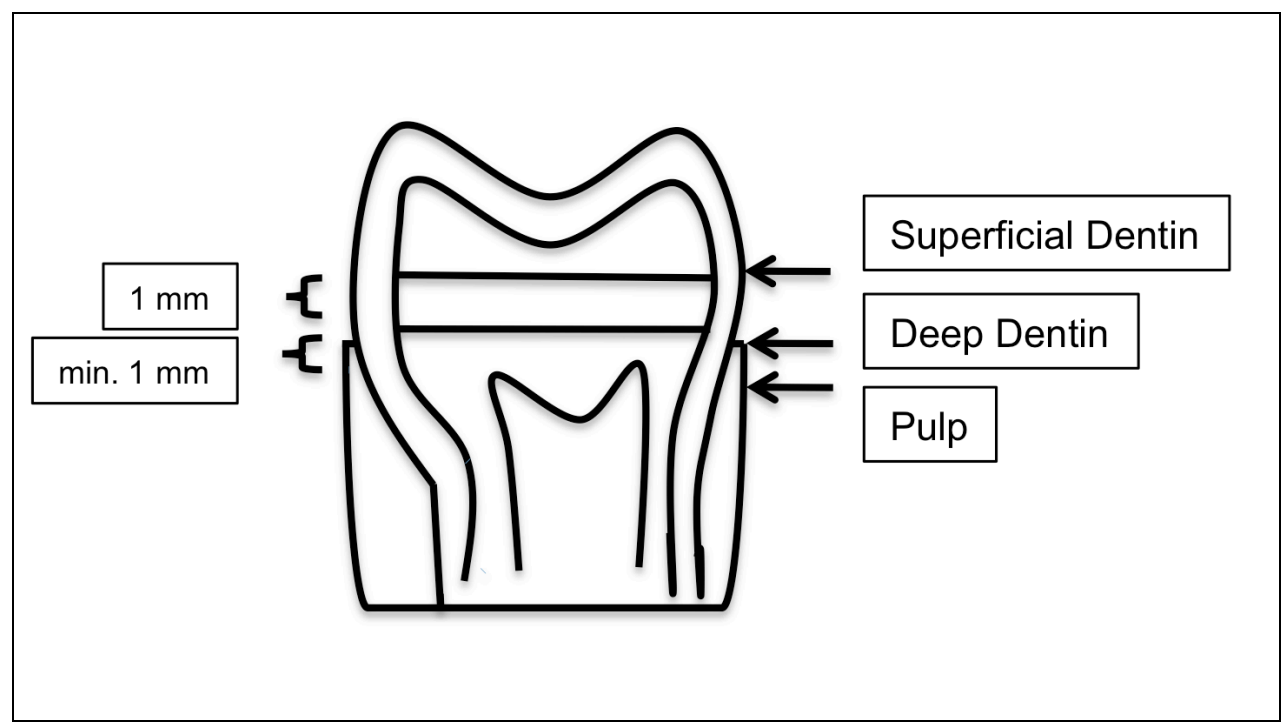

Fig. 1 Sketch of the position of superficial and deep dentin in relation to the cusp tips and pulp horns. Note that 1 $\mathrm{mm}$ below superficial dentin was considered as deep dentin. With X-rays it was made sure that dentin was available at least $1 \mathrm{~mm}$ above the pulp horns

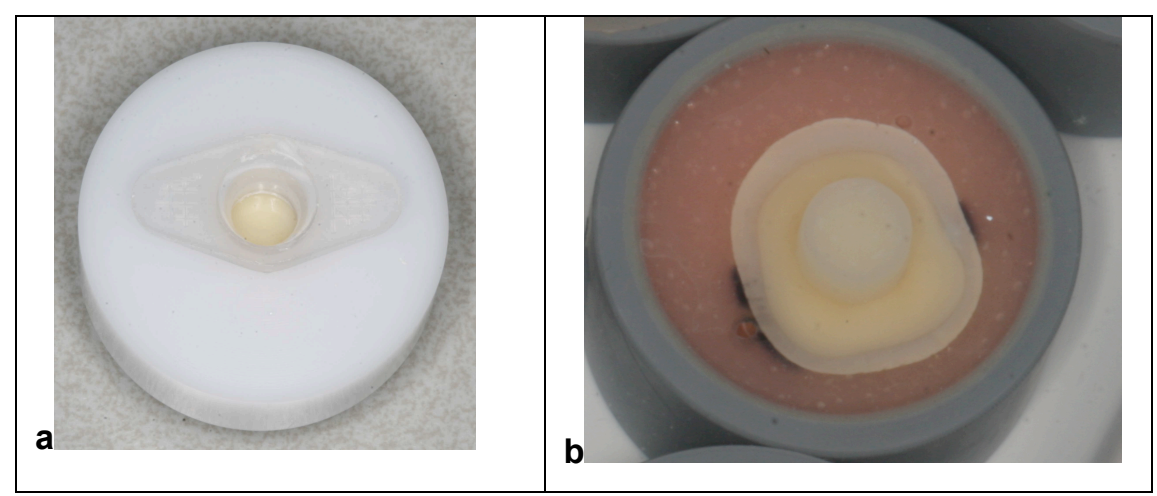

Figs. 2a-b a) Cement was applied incrementally in the polyethylene molds, not exceeding $2 \mathrm{~mm}$, and polymerized accordingly. b) Bonded cement on the dentin surface after removal of the mold 